\title{
HUMAN PROBLEMS OF INDUSTRIAL COMMUNITIES
}

$\mathrm{H}$ R.H. The Duke of Edinburgh's Study Conference on the Human Problems of Industrial Communities within the Commonwealth and Empire - to give it its full title-looked at first sight an intellectually unmanageable proposition. The intention was to collect about 280 members, ninety from the United Kingdom and the remainder from overseas, half managers and half trade unionists, for three weeks, of which the first and last period would be in Oxford and the centre ten days spent, in twenty groups, visiting factories and social institutions in twenty principal cities of England, Scotland and Wales. The members were not to be intellectuals or research workers, but men in the early prime of life actively engaged in industry either as managers or worker/trade unionists. The bill of fare for the Conference fell into four stages. First, the circulation, three months in advance, of twenty-five "Background Papers", dealing either with practical problems as seen by a practical man ("Stabilization of Labour in the Rhodesian Copperbelt", by Sir Ronald Prain), or with more general problems seen academically " "The Will to Work", by Prof. C. A. Mace; "Work and Community in a Primitive Society", by Prof. Raymond Firth). Second, a series of ten major addresses in plenary sessions at Oxford, with some very short group-discussion periods to enable the members to meet one another. Third, the "Study Tours", in which the whole Conference dispersed in groups of fourteen members with the addition of a specially selected United Kingdom chairman, each group spending about five days in a provincial city and its neighbourhood and four days in London. Fourth, a period of three days intensive group discussion in Oxford, followed by oral reports from groups and a general summary.

At first sight, the Conference ran with outstanding success. After more than two years of intensive preparation, the members, in almost exactly the planned proportions, and of very high quality, arrived in Oxford on July 8 and were swept through the programme, from the impressive opening ceremony in the Sheldonian to the final dinner in Christ Church on July 27, without a major hitch. All the incidental values (and they are not to be undervalued) were realized : the mixing of nationalities and industrial 'sides', the total absence of colour-consciousness, the sense of fellowship and common search. Nevertheless, it remains to ask three important questions : Was the subject-matter, so handled, manageable? Did the members absorb new ideas to any useful extent? What lasting effects can the Conference hope to have achieved?

Possible criticisms are obvious and formidable. It is acknowledgedly a difficult matter to hold the attention of such differing groups as sugar plantation workers in the Caribbean and Canadian electronic engineers. How could any programme the wit of man could devise suit both? Again, it is supposedly true that education, particularly via discussion groups, does not go very well when the gap in background and intellectual sophistication between the students is too wide-and it is hard to imagine wider gaps than those which existed in this Conference. Finally, the practical experience of the study tours was, of necessity, a rapid survey of certain problems of the United Kingdom, utterly unlike those of Pakistan or Sierra Leone or Johannesburg, and of necessity dimly comprehended and inaccurately interpreted.

\section{Common Problems}

These are formidable objections. Yet the conviction of a great number of intelligent members contradicts them flatly. My own answer to this conundrum was found in the recollection that industrialism is, in the full sense, a culture. It is so easy to recognize this about the past-historians and anthropologists speak readily of, say, pastoralism and the complex of religious, social and economic patterns of life associated with it. 'Industrialism', too, means more than certain manufacturing techniques; it has been based on a certain philosophy, it has raised certain political problems, it has set a certain social pattern wherever it has appeared. Examination of some of these associated effects of industrialization may be the best way of explaining why this diverse body of Conference members, from diverse backgrounds, in fact found a common language.

In the first place, the factory itself is a major and new political event. To hold some hundreds of men together, over long periods of time, in co-operation towards a single end, has only been achieved in history-on any wide scale-by three methods : slavery, military discipline or monastic discipline. The factory poses entirely new problems. From whence is the authority of 'the management' derived ? What are its sanctions, and its limits? If we are to speak of leadership rather than authority, what are the common purposes between leader and led which can provide the continuing reason for consent? These are common problems "whether on the shores of Asia or in the Edgware Road". Within them lies the problem of personal and group satisfaction at work.

Again, and still in the political field, industrializa. tion involves a shift of power away from old landowning and aristocratic groups; it means a rapid erosion of the influence of hereditary status (birth, chieftainship, caste) and the emergence of a new group of technical, administrative and professional leaders. This is true in Britain, and it is becoming clear in India (Mr. Tata explicitly commented on it in his address), in Africa and in Fiji. It is interesting that the newer societies, such as Australia, never greatly felt this problem, because industrialization has developed in almost pure form with no earlier culture to compete with. Moreover, not only does power shift, but also it tends to become centralized, both in the community and in government, by the growth of industrial combines and by the increasing need for State intervention and planning. This has been seen in Britain in developed form, despite our conscious efforts - not wholly unsuccessful - to retain and bolster local government and local initiative.

This leads directly to a third common effect. The industrial 'exchange economy' leads to a final break with the older subsistence economy based on the land. Once the 'worker' becomes wholly dependent on 'finding work', and has neither land nor tools of 
production to fall back upon, he is perilously dependent on the stability of the economy-the maintenance of 'full employment'. Far richer, but far more complex, the man-made industrial economy demands a rnan-devised fashioning of society-all the insurances against temporary breakdown which we call social security, diversification of industry, indeed every form of planned social control. Hence the growth of a planning and executive central State.

Three more common problems must be mentioned briefly, because all three occupied so much of tho discussions in the Conference : the impact on family life, the ehange in the nature of community life, and the quest for social ideals. In certain ways they are connected. As both the mother and the younger members of the family are sucked into independent wage-earning employment, the authority of the head of the family weakens, the older people, once 'retired', tend to be pushed on one side, and ideals of individual personal development weigh more and more heavily against the institution of family and 'home'. So also the peculiar form of industrial urbanization in the big city swamps the institutions of village social life and is apt to leave a mass of atomized individuals instead of a social structure. Both these changes, so obviously connected with the needs of industry both for concentration and for mobility, raise the question of social ideals: Are the needs of production, the aim of material success, to dominate and exclude age-old values of personal and social life?

\section{The Impact of Industrialization}

It was around these common problems that the main addresses to the Conference fell. After the opening address by the Duke of Edinburgh-by common consent a brilliant and obviously personal contribution-with its emphasis on humility and study, and on the aims of a civilization rather than the wealth of an economy, Sir John Maud struck the keynote of the Conference work by his speech on "The Impact of Industrialization". Outstanding in my memory of this memorable address, and in its effect on the Conference, were a series of paradoxes. Industrialization can bring, said Sir John, more freedom and more slavery : more loneliness and more fellowship : more civilization and more barbarism. Which way the balance tilts hangs on the personal philosophy, courage, faith and effort of the myriad individuals within society.

Thereafter came a series of addresses, the titles of which show their drift. "The Varying Pattern of Industry", by Lord Citrine; "The Human Problems of Industry", by Mr. Waring, Mr. J. M. Campbell, Sir Alfred Roberts, Mr. J. Crawford, Colonel Grierson; "Everyday Relations of Industry and the Community Around It", by Sir Harry Pilkington and Dame Florence Hancock ; "The Two PartnershipsMan with Man and Man with Nature", by Sir Harold Hartley. In the last period at Oxford the discussions were supplemented by five more addresses in a series of "Overseas Viewpoints": "The New Industrial Communities in West Africa", by Mr. R. K. A. Gardiner (Gold Coast); "The Future Responsibilities of Trade Unions", by Mr. A. E. Monk (Australia) (owing to illness, this paper was circulated in written form); "Industrial Problems in a Multi-racial Society", by Mr. H. F. Oppenheimer (South Africa); "Thoughts on the Industrialization of a Predominantly Rural Society", by Mr. J. R. D. Tata (India); "The Effects of Technical Change", by Mr. W. J. Bennett (Canada).
All these addresses were more than able; but beyond question, if we take the addresses of the Duke of Edinburgh and Sir John Maud as the first high points, Sir Harold Hartley's as the second, then Mr. Gardiner's speech, closely followed by Mr. Oppenheimer, was the third, and in certain respects, the highest. Speaking with the most palpable sincerity and controlled feeling, Mr. Gardiner put forward the thesis for equal respect for the human dignity of the individual of whatever race, religion or colour, as the only real basis upon which the future of the Commonwealth could rest. "The individual ought to feel that certain things cannot happen to him as a person, not because he belongs to a privileged group or race." "We can form a society on a set of rules; but if we intend to form a community-and that is what, to me, a Commonwealth means-that can only be formed on the basis of a common understanding or outlook, a common ethos. Is it going to be possible for us to develop this common outlook, to make it possible for us to continue to set an example to the rest of the world ?"

"For us to continue...". Perhaps these words do not look startling in print; but from the speaker, on the occasion, they moved the whole Conference to an ovation reserved for no other speaker save the Duke of Edinburgh himself. Followed, as they were, by a practical, statesmanlike and liberal speech by Mr. Oppenheimer, tackling the problem of Southern Africa foursquare (and, if it had not been tackled, it would have been an abscess in the Conference), they confirmed finally a sense, already growing, that this Conference was not merely a successful façade but an event in which things of lasting importance were happening as day followed day.

\section{Industry and Social Service}

Each group of members, fifteen in number including their chairman, spent ten days 'on tour', seeing representative men and women in industry and social service in a very intensive programme based primarily on discussion, with only enough sight-seeing of factories or schools to give atmosphere and background. In fact, the discussion seems to have been admirably frank and full-several factories referred to it afterwards as more like an inquisition than a visit. Each group was given three subjects for special study, and the final reporting, dealing with these special subjects in groups and consecutively, covered the main field of the whole conference.

What came out of these reports? A remarkable unanimity in five or six directions. Smaller working groups where the supervisor really can supervise personally and the manager can manage; personal relationships and personal trust as a factor transcending all other 'incentives' and 'conditions at work'; independent social activity by the community, not managed by the factory; opposition to the employment of married women with young children ; restoration of the central importance of family life; the need for spiritual values. When the oral reports are published, these will be some of the leading themes.

It is true that to many people these are platitudes. But fifteen years ago they were in the mouths, not often of 'practical men' but of the so-called intellectuals, social scientists, psychiatrists and anthropologists. It is of real importance that this is now the talk of practical men from all eorners of the 
Earth-trade unionists and managers alike. Ideas have moved not only out through society from their intellectual fountainhead, but outwards throughout the Commonwealth; and they are the same ideas, whether in Nigeria or Pakistan.

Writing fresh from the impact of this meeting, which developed an atmosphere of common effort which, in the Duke of Edinburgh's words, you could cut with a knife, I am bound to over-estimate the effects of this event. Yet that it was an event, with its own tiny place in the story of the Commonwealth, I am convinced. The members, when they return to the intrigues, the disappointments, the prejudices and the passion of real life in their countries (conferences are never real life) will carry back with them not only an experience of friendship-and that was abundantly evident-but also a reinforcement of faith and hope. Is anything of more value ?

GuY HunteR

\section{PHYSICS OF GAS FLOW AT VERY HIGH SPEEDS}

$\mathrm{T}$ HE summer discussion meeting of the Physical Society was held in the University of Manchester during July 16-17 under the auspices of the Departments of Applied Mathematics and of the Mechanics of Fluids. The subject was "The Physics of Gas Flow at very High Speeds", that is to say, speeds so high that changes in kinetic energy are comparable with the energy required to produce interesting physical changes such as dissociation, ionization and substantial emission of radiation. The implications for the aerodynamics of man-made projectiles travelling at extreme speeds, and also of meteors, were included in the discussion. The shock tube, the principal research tool in this field, was discussed at length, both as regards design and instrumentation for use with very strong shock waves, and in connexion with the results so far discovered by its use. Prof. S. Devons, vice-president of the Society, presided over the meeting.

As Prof. M. J. Lighthill, of the Department of Mathematics, University of Manchester, said in his introductory remarks, the object of the meeting was to promote studies in a field where two great new scientific disciplines of the twentieth century meet and overlap. These disciplines are, on one hand, chemical kinetics, as grounded theoretically on the study of collision processes and experimentally on spectroscopy as interpreted by the quantum theory of radiative transitions; and on the other hand, fluid dynamics, as it has grown up since the discovery of the basic concepts of the boundary layer and the shock wave during the first decade of this century, using the wind-tunnel as the principal experimental tool. Neither subject had yet reached the dignified status of a science in the nineteenth century, when as Sir Cyril Hinshelwood has observed, chemical reactions were classified mainly into those that go and those that do not go, and when fluid dynamicists were divided into hydraulic engineers who observed things that could not be explained and mathematicians who explained things that could not be observed. In the great, and largely successful, struggles of the past fifty years to reach some sort of systematic understanding in both these two fields, the scientists involved were naturally disinclined to complicate their problems by introducing ideas from quite different disciplines. So until very recently it has been the rule for fluid dynamieists to know almost no physical chemistry, and physical chemists almost no fluid dynamics.

During the past five years, however, a movement has grown up with the object of making new advances by pooling the knowledge that has been acquired in these fields. To this end, fluid dynamicists have set themselves to learn about chemical kinetics and students of chemical kinetics have started to study fluid dynamics. These herculean labours have already begun to make important improvements in our knowledge of combustion processes, and a number of conferences have been held in this field. More recently still, external aerodynamics (that is, the study of flow around projectiles moving through the atmosphere) has reached the stage where this pooling of ideas is necessary. To mention an extreme example, it has been announced in the House of Commons that the Americans propose to shoot at Ascension Island from their missile-testing station in Florida. A simple computation of the elliptic orbit which such a missile would have to follow (after it has left the atmosphere and its rocket motors have burnt out) shows that it would have to re-enter the atmosphere with a speed of at least $6 \mathrm{~km}$. $/ \mathrm{sec}$. But a speed of half this would already be sufficient to cause considerable chemical changes in the air around a projectile. These changes would involve dissociation of oxygen and nitrogen molecules into free atoms, as well as the formation of nitric oxide. At speeds of $6 \mathrm{~km}$./ $/ \mathrm{sec}$. the dissociation of oxygen near the front of the projectile would be nearly complete, and that of nitrogen well advanced. These changes may be expected to have important effects on the airflow about the body, and hence on the aerodynamic heating which is, of course, what constitutes the main difficulty of flight at these speeds. They constitute the main reason why aerodynamicists have been learning chemistry.

The reason for the converse process is the development of the shock tube, which physical chemists have found increasingly useful for studying fast gas reactions since Kantrowitz advocated its use for this purpose five years ago. Developed originally for studying the fluid dynamics of shock waves under conditions far more flexible than could be obtained in wind-tunnels, it has found additional use as a means of studying how reactions proceed in time after the pressure and the translational temperature of a gas mixture have been instantaneously raised by known amounts. For example, the shock tube has been used in this way to determine the rates of dissociation of iodine, bromine and nitrogen tetroxide. Since the shock tube is so useful both in this kind of work and in studying problems of very-high-speed aerodynamics, two of the five main lectures at this conference were devoted to it.

After giving this introduction Prof. Lighthill then proceeded to read his own lecture on the dynamics of a dissociating gas. He began by outlining the scientific advantages of starting, in such a difficult 